\title{
The Addition of Strength Training to Practice of High Intensity Group Gymnastics May Not Imply in Highest Levels of Strength and Quality of Life: A Cross-Sectional Study
}

\author{
Bruno Henrique da Silva1, Bruno Allan Vieira², Rodrigo Sudatti Delevatti2 (1) \\ ${ }^{1}$ Sogipa Faculty of Physical Education, Porto Alegre, Brazil \\ ${ }^{2}$ Santa Catarina Federal University, Florianópolis, Brazil \\ Email: brunosilvapersonal@live.com,bruno_allan1998@hotmail.com,rsdrodrigo@hotmail.com
}

How to cite this paper: da Silva, B.H., Vieira, B.A. and Delevatti, R.S. (2019) The Addition of Strength Training to Practice of High Intensity Group Gymnastics May Not Imply in Highest Levels of Strength and Quality of Life: A Cross-Sectional Study. Health, 11, 896-904.

https://doi.org/10.4236/health.2019.117072

Received: May 17, 2019

Accepted: July 9, 2019

Published: July 12, 2019

Copyright $\odot 2019$ by author(s) and Scientific Research Publishing Inc. This work is licensed under the Creative Commons Attribution International License (CC BY 4.0).

http://creativecommons.org/licenses/by/4.0/

(c) (i) Open Access

\begin{abstract}
The aim of the present study was to compare the levels of maximum strength, endurance muscular and quality of life among practitioners of group gymnastics (IG) of isolated form and practitioners of group gymnastics combinated with strength training (CG). This study is characterized as observational of comparative cross-sectional design. The sample was composted by young women, trained at least for three months, without health complications. Maximum strength (1RM) and endurance muscular (repetition at $60 \%$ $1 \mathrm{RM}$ ) of the lower limbs were evaluated in knee extension exercise, unilaterally. Overall quality of life and in four domains was evaluated by the WHOQOL-bref. Data were described by mean and standard deviation values. Outcomes were compared by independent $t$-test, adopting a significance level (a) of 0.05 . Thirty women were evaluated (isolated gymnastic (IG), $\mathrm{n}=15$; $30.13 \pm 7.24$ years-combined gymnastic and strength (CG), $\mathrm{n}=15 ; 29.46 \pm$ 8.18 years). Similarly values were found among groups for all outcomes ( $p>$ 0.05). The results suggest that the association of strength training with gymnastics training, possibly accumulating excessive training volume, may not increase the levels of maximum strength, endurance muscular and quality of life in young women.
\end{abstract}

\section{Keywords}

Resistance Training, Gymnastic, Gym, Exercise Training, Quality of Life

\section{Introduction}

It's known that the practice of exercise training is extremely important for health 
[1]. Specifically, in women, there are several benefits in all ages [2]. Thus, to improve physical fitness components such as muscular strength and endurance can bring several positive adaptations to health and quality of life. These benefits are common objectives in practitioners of many training modalities, such as group gymnastics and strength training, in which are very sought by young women.

Many popular gymnastic modalities, such as Zumba and Spinning, are understood as aerobic activities of moderate to high intensity, with great caloric expenditure, usually aiming to improve cardiorespiratory fitness [3]. According to Liebl et al. [4], this type of modality helps to decrease fat percentage and increase lean body mass, thus facilitating everyday activities. Another type of training able to increase the lean mass and much practiced by young women is strength training. According to Dias et al. [5], strength training provides important morphological, neuromuscular and physiological alterations, besides social and behavioral improvements. The demand of the female public in gyms by gymnastics group and/or strength training is very high, and these modalities must be studied not only isolated, but also in their combination, a format commonly adopted by the practitioners. Separately, both modalities (gymnastics group in their different manifestations and strength training) are accepted as beneficial, but there is little evidence of training concurrent with these modalities.

Paulo et al. [6] quote out that there is negative interference in performance when aerobic training is combined with strength training in the same training period. This statement corroborates Cadore et al. [7] who mention that strength training simultaneously to aerobic training results in inferior neuromuscular adaptations to isolated strength training. Some hypotheses related to this fact may be the overwork performed and the lack of rest, thus not having an adequate muscle recovery.

One of the purposes of sports training and exercise training is the improvement of physical capacities. When training is excessive and prolonged along with inadequate recovery, many of the positive physiological adaptations related to physical training are reverted in negative changes and even overtraining [8]. Therefore, in order to avoid overtraining, some care can be considered in structuring the training, such as to train strength and aerobic exercises on different days and to respect periods of muscle recovery appropriately [6]. In this direction, when training program has primary aim of improving maximal strength or muscle power by the performing of combined training (aerobic and strength), it is indicated to perform the modalities in alternate days or perform the training in strength-aerobic order, always adjusting prescription according with training status of the individuals [6] [9] [10].

Although the advances of the concurrent/combined training area are large, the studies generally used cyclic modalities of aerobic training, such as walking, running and cycling [11] [12] in training models that differ, at least in part, from what is most trained in "real world gyms" by some populations. Moreover, the outcomes of major interest in this area are generally variables of physical fitness, 
especially muscular strength, lacking an enlarged view of what the combination of modalities in a "real world" perspective causes in quality of life. This gap is even greater when the subject is analyzed in young female public, for little is investigated regarding the performance of group gymnastics isolated or combined with strength training. Thus, it is necessary to investigate whether the combination of strength training and group gymnastics provides additional gains of muscular strength and endurance, as well as quality of life, compared to group gymnastics only. Aiming to partially fill these gaps, the present study had as objective to compare the levels of maximum strength, endurance muscular and quality of life among practitioners of isolated group gymnastics and practitioners of group gymnastics combined with strength training. Such as hypothesis, it is believed that due to a possible excess of muscle work with inadequate recovery, maximum strength and muscular endurance, as well as quality of life, are not different between the groups.

\section{Methods}

\subsection{Study Design}

The present study adopted a quantitative, comparative cross-sectional approach in which the levels of maximum strength, muscular endurance and quality of life were analyzed in two distinct groups, being them: Isolated Gymnastics (IG) and Combined Gymnastics with strength training (CG).

\subsection{Participants}

The study had 30 women of 18 to 50 years old, enrolled in a gym located in the city center of São Leopoldo, RS, Brazil. All participants were training systematically for at least three months. Of the total of 30 participants, 15 performed only group gymnastics training (IG) and the other 15 performed group gymnastics combined with strength training (GC). The recruitment of the sample was non-probabilistic, on a voluntary basis. First, all participants that performed group gymnastics combined with strength training were invited to participate of the study. After, these individuals were paired with practitioners only of group gymnastics. All participants were informed of the methodological terms of the present study and signed a free and informed consent term. The reading and signing of the consent term were performed individually, prior to the data collection.

Among the gymnastics modalities practiced by the participants of the research were zumba, spinning, piloxing and functional training, which are performed weekly in gym. As inclusion criterion, participants should be participating in at least two sessions per week. The same was valid for strength training, in which each participant performed a specific training using equipments and free weights, with exercises for the whole body.

\subsection{Experimental Procedures}

The access to the gym was carried out, first, through a conversation with the 
coordination and direction of the same, in which the objective of this research was presented. After agreement of the coordination and direction of gym, a list of contacts of the young women was requested, going through an analysis and possibly a first contact. In this first contact with the possible participants, invitation was made and for those that agreed in participate, consent term was sent, and after signed terms, were performed familiarizations with the physical tests, sample characterization data collection and lastly, outcomes data collection.

For data collection, one participant was set at every 30 minutes, and all participants performed an anamnesis and familiarization with the test protocol. The time of collection was scheduled according to the availability of the participants, being carried out on weekdays and also on saturdays. During the collection period, the ratings of perceived exertion (RPE) corresponding to the Borg Scale (6 to 20 points) were also collected with all participants during the group gymnastics sessions, identifying the intensity in the middle and at the end of the sessions.

To data collection, the evaluator was trained under the measurement instruments and collection protocols used. The participants should have been for at least one day without training to perform the collect.

1) Maximum strength and muscular endurance

To evaluate the maximal strength of lower limbs it was used one repetition maximum test (1RM) in the knee extension exercise, performed unilaterally, with the dominant lower limb. Firstly, the participants performed a five-minute warm-up on a cycle ergometer. After, a load was selected with the intention that subjects performed a maximum of 10RM, also with the aim of familiarizing them with the equipment and the movement to be performed.

After the participants have performed the maximum number of repetitions possible, the load was resized, in order to find the load related to $1 \mathrm{RM}$, using the coefficients of LOMBARDI [13]. This occurred until the maximum load to be found. A maximum of five attempts were made, with a five-minute interval between them. The adopted rhythm was 1.5 seconds for the concentric phase and 1.5 seconds for the eccentric phase, which was controlled by metronome.

2) For determination of the muscular endurance, participants performed the maximum number of repetitions with $60 \%$ of $1 \mathrm{RM}$, following the same rhythm of the 1RM test ( $1.5 \mathrm{seg}$ for each phase-concentric and eccentric) and range of execution pre-established.

3) Quality of life

Quality of life was evaluated by the WHOQOL-bref [14] Portuguese version. This questionnaire is composed of 26 questions with alternatives from 1 to 5 , which generate scores of general quality of life, and in four domains, being these the Physical, Psychological, Social and the Environment.

4) Anthropometry

Anthropometry variables were used for sample characterization. Were measured height and body mass, in which the Body Mass Index (BMI) was calculated, by the equation (body mass/height ${ }^{2}$ ). Waist circumference also was measured, at 
the midpoint between the last rib and the iliac crest.

\subsection{Statistical Analysis}

The normality and the homogeneity of the data were evaluated by the Shapiro-Wilk and Levene tests, respectively. As the data were normal, the values of mean and standard deviation were used as descriptive statistics. The comparison between the two groups was performed using the independent $t$-test, adopting a level of significance of 0.05 . All analyzes were performed in the SPSS program, version 20.0.

\section{Results}

As sample characterization, age and anthropometric characteristics of the participants are presented in Table 1.

In Table 2 are presented the results of maximum strength and muscular endurance. It was observed that there was no difference between the groups studied for maximal strength and muscular endurance of the lower limbs.

In Table 3, overall quality of life and in four different domains are presented.

Table 1. Characterization of the sample in the isolated gymnastics group (IG) and combined gymnastics with strength training group (CG).

\begin{tabular}{cccc}
\hline Variables & IG $(\mathrm{n}=15)$ & GC $(\mathrm{n}=15)$ & $\mathrm{p}$ \\
\hline Age (Years) & $30.13 \pm 7.24$ & $29.46 \pm 8.18$ & 0.815 \\
Body mass $(\mathrm{kg})$ & $68.71 \pm 7.58$ & $67.36 \pm 9.23$ & 0.664 \\
Heigth $(\mathrm{m})$ & $1.65 \pm 0.05$ & $1.66 \pm 0.06$ & 0.829 \\
BMI $\left(\mathrm{kg} / \mathrm{m}^{2}\right)$ & $25.07 \pm 2.56$ & $24.39 \pm 2.66$ & 0.483 \\
Waist circumference $(\mathrm{cm})$ & $81.47 \pm 8.45$ & $80.54 \pm 8.49$ & 0.767 \\
\hline
\end{tabular}

BMI: Body Mass Index; $\alpha$ : 0.05 .

Table 2. Strength and muscular endurance in isolated gymnastics group (IG) and in combined gymnastics with strength training group (CG).

\begin{tabular}{cccc}
\hline Variables & IG $(\mathrm{n}=15)$ & GC $(\mathrm{n}=15)$ & $\mathrm{p}$ \\
\hline Maximum strength $-1 \mathrm{RM}(\mathrm{kg})$ & $35.53 \pm 8.21$ & $39.20 \pm 7.96$ & 0.225 \\
Muscular endurance (rep) & $13.13 \pm 2.92$ & $13.73 \pm 2.86$ & 0.575 \\
\hline
\end{tabular}

1RM: One repetition maximum, rep: repetitions; $\alpha$ : 0.05 .

Table 3. Overall quality of life and in different domains in the isolated gymnastic group (IG) and combined gymnastics with strength training group (CG).

\begin{tabular}{cccc}
\hline Variables & IG $(\mathrm{n}=15)$ & $\mathrm{GC}(\mathrm{n}=15)$ & $\mathrm{p}$ \\
\hline QL-Physical domain & $77.61 \pm 12.47$ & $75.47 \pm 10.78$ & 0.619 \\
QL-Psychological domain & $75.55 \pm 9.43$ & $71.11 \pm 10.73$ & 0.238 \\
QL-Social domain & $77.22 \pm 15.57$ & $80.00 \pm 10.35$ & 0.570 \\
QL-Environmental domain & $70.41 \pm 10.01$ & $67.91 \pm 9.40$ & 0.487 \\
QL-Overall & $82.50 \pm 11.37$ & $76.66 \pm 12.38$ & 0.190 \\
\hline
\end{tabular}

QL: Quality of life; $\alpha$ : 0.05 . 
As for neuromuscular outcomes, no differences were found between the groups in relation to overall quality of life and in the four domains analyzed.

\section{Discussion}

The findings of the present study indicate that young women practitioners only of group gymnastics may present similar muscular strength and endurance, and quality of life to young women practitioners of group gymnastics combined with strength training.

In a first moment, the similarity found between groups, especially for neuromuscular outcomes can be considered controversial, for people trained in strength should have higher neuromuscular fitness compared to your pairs trained in exercise modalities predominantly aerobic. However, when these modalities are analyzed of more specific form, it is possible to understand least in part our results. The intensity reported by the major part of sample in the gym sessions was the RPE 17, referring to very intense (Borg scale). By the relationship showed by some authors [15] [16] between this point (RPE 17) and the second metabolic threshold it is plausible that in group gymnastic there was a expressive recruitment of type II fibers, use of muscle glycogen, being a concurrent stimulus for the strength training in neuromuscular adaptations.

In the literature there are divergent results regarding the effects of aerobic training simultaneously to strength training for strength and muscular endurance outcomes. In study of Cadore et al. [11] with elderly men, after 12 weeks of training was observed that the strength group had strength gains of lower limbs of greater magnitude (67\%) than the concurrent training group (41\%), the same did not occur with upper limbs, strengthening the hypothesis that the aerobic component of the combined training can influence negatively in the muscle strength gains of lower limbs. However, in present study all participants performed different and acyclic modalities of aerobic training, lacking one group trained only in strength for better understanding the impact of the two (gymnastic and strength) modalities trained in neuromuscular adaptations. Also it is importantly considered the sex and age difference between the samples of the studies. In another study with elderly men and intervention of 16 weeks, Izquierdo et al. [17] not found differences in muscle strength between the one group trained only in strength and one group that trained of combined form (strength and aerobic), demonstrating that the aerobic component did not negatively influenced muscle strength gains.

In another study of Izquierdo et al. [18] with middle-aged men, one of the objectives was to compare levels of lower limbs muscle strength in different training models, in which the groups were divided into strength, concurrent and aerobic. Strength and concurrent training groups presented statistically better results than aerobic group. Different of our findings, the concurrent training was more effective for lower limb muscle strength in relation to group that underwent only aerobic training. However it is worth mentioning that the participants 
in present study were women trained, while in study of Izquierdo et al. [10] were untrained men, besides of the differences in training variables, especially in weekly frequency, because while in cited study [10] had 1 to 2 days a week of training, present study as performed in a transversal design in which participants trained in "real context", generally above to 2 days a week..

The mostly aforementioned studies use cyclical aerobic training, such as walking, running and cycling, thus arising the need for studies with acyclic and collective modalities. In this sense, Fernandes et al. [19] emphasize the importance of didactic-pedagogical planning in group gymnastic sessions, since the results found in their research are that localized gymnastics is an excellent way to train strength, considering that it was found similarly muscle strength gain to strength training, thus helping to overturn the paradigm that only the strength training is beneficial for strength muscle.

Regarding quality of life, the results follow the same direction. It is possible that similar fitness status, as neuromuscular outcomes, leads to similar functionality, a factor that can in part explain quality of life results. The fact is that with basis in our study, the addition of the other modality (strength training) does not add benefits in the overall quality of life and in its different domains in comparison to practice of isolated group gymnastics.

Analyzing in general all findings and discussions about the study, it is indicated for young women, who desire adequated maximum strength and muscular endurance, as well as a good quality of life, a care in the structuring of the training, especially in relation to the weekly distribution of the training modalities and the control of the intensity that these represent, fulfilling a suitable recovery time between intense sessions, so that the physical capacities can be developed without excessive volume and intensity of training.

The fact that the prescription of strength training is not totally similar among the participants may limit the discussion from the point of view of training variables (specificity, volume, intensity and objectives). Another limitation is the small $n$ sample and the only local of recruitment (gym). However, as strengths we highlight the analysis of important outcomes in a real, externally valid training scenario, in which trained women were studied in the face of a still neglected in exercise study are, which is the addition or not of strength training to the routine of group gymnastics practitioners.

\section{Conclusion}

Based in our results, it can be concluded that the association of strength training with group gymnastics training performed in high intensity, possibly accumulating excessive muscle work, does not increase strength, muscular resistance and quality of life in young women.

\section{Conflicts of Interest}

The authors declare no conflicts of interest regarding the publication of this 
paper.

\section{References}

[1] Warburton, D.E.R., Nicol, C.W. and Bredin, S.S.D. (2006) Health Benefits of Physical Activity: The Evidence. Canadian Medical Association Journal, Ottawa, 176, 801-809. https://doi.org/10.1503/cmaj.051351

[2] Silva, D.K. (2002) Atividade física e qualidade de vida relacionada à saúde de mulheres com doenças vascular periférica. Universidade Federal de Santa Catarina, Florianópolis, SC, Mestrado em Educação Física.

[3] Santos, J.C.L.D., Costa, P.D.D. and Rossato, M. (2014) Alterações na cinemática do membro inferior durante exercícios de ginástica com botas Kangoo Jumps. Uruguaiana-RS. V Simpósio de Neuromecânica Aplicada, 131-141.

[4] Liebl, E.C., Mascarenhas, L.P.G., Gonçalves, R., Lima, V.A., Souza, W.B., Grzelczak, M.T. and Souza, W.C. (2014) Comparação dos efeitos da ginástica localizada e musculação nos níveis de resistência muscular localizada e força em mulheres. Revista Acta Brasileira do Movimento Humano, 4, 1-12.

[5] Dias, R.M.R., Cyrino, E.S., Salvador, E.P., Nakamura, F.Y., Pina, F.L.C. and Oliveira, R. (2005) Impacto de oito semanas de treinamento com pesos sobre a força muscular de homens e mulheres. Revista Brasileira de Medicina do Esporte, 11. https://doi.org/10.1590/S1517-86922005000400004

[6] Paulo, A.C., Souza, E.O., Laurentino, G., Ugrinowitsch, C. and Tricoli, V. (2005) Efeito do treinamento concorrente no desenvolvimento da força motora e da resistência aeróbia. Revista Mackenzie de Educação Física e Esporte, 4.

[7] Cadore, E.L., Pinto, R.S. and Kruel, L.F.M. (2012) Adaptações neuromusculares ao treinamento de força e concorrente em homens idosos. Revista Brasileira de Cineantropometria \& Desempenho Humano, 14, 483-495. https://doi.org/10.5007/1980-0037.2012v14n4p483

[8] Armstrong, L.E. and Van Heest, J.L. (2002) The Unknown Mechanism of the Overtraining Syndrome: Clues from Depression and Psychoneuroimmunology. Sports Medicine, 32, 185-209. https://doi.org/10.2165/00007256-200232030-00003

[9] Cadore, E.L., Pinto, R.S., Bottaro, M. and Izquierdo, M. (2014) Strength and Endurance Training Prescription in Healthy and Frail Elderly. Aging and Disease, 5, 183-195. https://doi.org/10.14336/AD.2014.0500183

[10] Sillampää, E., Häkkinen, A., Nyman, K., Cheng, S., Karavirta, L., Laaksonen, D.E., Huuhka, N., Kraemer, W.J. and Häkkinen, K. (2008) Body Composition and Fitness during Strength and/or Endurance Training in Older Men. Medicine \& Science in Sports \& Exercise, 40, 950-958. https://doi.org/10.1249/MSS.0b013e318165c854

[11] Cadore, E.L., Pinto, RS., Lhullier, F.L.R., Correa, CS., Alberton, C.L., Pinto, S.S., Almeida, A.P., Tartaruga, M.P., Silva, M.P. and Kruel, L.F. (2010) Physiological Effects of Concurrent Training in Elderly Men. International Journal of Sports Medicine, 31, 689-697. https://doi.org/10.1055/s-0030-1261895

[12] Karavirta, L., Tulppo, M.P., Laaksonen, D.E., Nyman, K., Laukkanen, R.T., Kinnunen, H., Hakkinen, A. and Hakkinen, K. (2009) Heart Rate Dynamics after Combined Endurance and Strength Training in Older Men. Medicine \& Science in Sports \& Exercise, 41, 1436-1443. https://doi.org/10.1249/MSS.0b013e3181994a91

[13] Lombardi, V.P. (1989) Beginning Weight Training: The Safe and Effective Way. Wm. C. Brown, Dubuque.

[14] Fleck, M.P.A., Louzada, S., Xavier, M., Chachamovich, E.V.G., Santos, L. and 
Pinzon, V. (2000) Aplicação da versão em português do instrumento abreviado de avaliação da qualidade de vida "WHOQOL-Bref". Revista de Saúde Pública, São Paulo, 34, 178-183. https://doi.org/10.1590/S0034-89102000000200012

[15] Alberton, C.L., Antunes, A.H., Beilke, D.D., Pinto, S.S., Kanitz, A.C., Tartaruga, M.P. and Kruel, L.F.M. (2013) Maximal and Ventilatory Thresholds of Oxygen Uptake and Rating of Perceived Exertion Responses to Water Aerobic Exercises. Journal of Strength and Conditioning Research, 27, 1897-1903.

https://doi.org/10.1519/ISC.0b013e3182736e47

[16] Binder, R.K., Wonisch, M., Corra, U., Cohen-Solal, A., Vanhees, L., Saner, H. and Schmid, J.P. (2008) Methodological Approach to the First and Second Lactate Threshold in Incremental Cardiopulmonary Exercise Testing. The European Journal of Cardiovascular Prevention \& Rehabilitation, 15, 726-734. https://doi.org/10.1097/HJR.0b013e328304fed4

[17] Izquierdo, M., Hakkinen, K., Ibañez, J., Kraemer, W.J. and Gorostiaga, E.M. (2005) Effects of Combined Resistance and Cardiovascular Training on Strength, Power, Muscle Cross-Sectional Area, and Endurance Markers in Middle-Aged Men. European Journal of Applied Physiology, 94, 70. https://doi.org/10.1007/s00421-004-1280-5

[18] Izquierdo, M., Ibañez, J., Hakkinen, K., Kraemer, W.J., Larrion, J.L. and Gorostiaga, E.M. (2004) Once Weekly Combined Resistance and Cardiovascular Training in Healthy Older Men. Medicine \& Science in Sports \& Exercise, 36, 435-443. https://doi.org/10.1249/01.MSS.0000117897.55226.9A

[19] Fernandes, A.D.O., Novaes, J.S. and Dantas, E.H.M. (2004) Efeitos do treinamento de ginástica localizada e musculação nos níveis de força máxima de membros inferiores, superiores e lombar de mulheres adultas não atletas. Fitness \& Performance Journal, 3, 33-40. https://doi.org/10.3900/fpj.3.1.33.p 